Article

\title{
Wireless, Portable Fiber Bragg Grating Interrogation System Employing Optical Edge Filter
}

\author{
Ken Ogawa $\left.{ }^{1,3}{ }^{(}\right)$, Shouhei Koyama ${ }^{2, *}$, , Yuuki Haseda ${ }^{1}$, Keiichi Fujita ${ }^{3}$, Hiroaki Ishizawa ${ }^{4}$ and \\ Keisaku Fujimoto ${ }^{5}$ \\ 1 Graduate School of Science and Technology, Shinshu University, 3-15-1 Tokida, Ueda, \\ Nagano 386-8567, Japan \\ 2 Faculty of Textile Science and Technology, Shinshu University, 3-15-1 Tokida, Ueda, Nagano 386-8567, Japan \\ 3 Research \& Development Sec. Development Center, Naganokeiki Co., Ltd., 2150 Ikuta, Ueda, \\ Nagano 386-0411, Japan \\ 4 Institute for Fiber Engineering, Shinshu University, 3-15-1 Tokida, Ueda, Nagano 386-8567, Japan \\ 5 Department of Clinical Laboratory Sciences, School of Health Sciences, Shinshu University, 3-1-1 Asahi, \\ Matsumoto, Nagano 390-8621, Japan \\ * Correspondence: shouhei@shinshu-u.ac.jp; Tel.: +81-268-21-5572
}

Received: 10 June 2019; Accepted: 18 July 2019; Published: 22 July 2019

\begin{abstract}
A small-size, high-precision fiber Bragg grating interrogator was developed for continuous plethysmograph monitoring. The interrogator employs optical edge filters, which were integrated with a broad-band light source and photodetector to demodulate the Bragg wavelength shift. An amplifier circuit was designed to effectively amplify the plethysmograph signal, obtained as a small vibration of optical power on the large offset. The standard deviation of the measured Bragg wavelength was about $0.1 \mathrm{pm}$. The developed edge filter module and amplifier circuit were encased with a single-board computer and communicated with a laptop computer via Wi-Fi. As a result, the plethysmograph was clearly obtained remotely, indicating the possibility of continuous vital sign measurement.
\end{abstract}

Keywords: fiber bragg grating; vital sign monitoring; optical edge filter; pulse wave; plethysmograph

\section{Introduction}

The necessity of continuous vital sign monitoring has been increasing in many aging societies. As sensing equipment is downsized, continuous vital sign monitoring such as electrocardiograph (ECG) [1], phonocardiograph (PCG) [2] and photo-plethysmograph (PPG) [3,4] have become readily available. In such applications, users wear these monitors, so the whole system needs to be small, lightweight and portable.

The fiber Bragg grating (FBG) sensor is a strong candidate for such vital sign monitoring applications. The FBG is a diffraction grating inscribed in the core of an optical fiber, which reflects a specific wavelength, called the Bragg wavelength, of incident light [5]. The Bragg wavelength is changed with the strain and temperature induced on the FBG [5-7]. Because they have electromagnetic immunity and high sensitivity, FBG sensors have been used in a variety of applications such as structural health monitoring [8-10], vibration sensing under high electromagnetic noise [11,12] and as hydrophones $[13,14]$. Further, FBG sensors are much thinner than conventional electrical sensors, with almost the same diameter as a hair, and can be woven into textiles $[15,16]$. Considering these advantages, several studies have investigated the use of FBG sensors in vital sign monitoring [17-22]. For example, ballistocardiograph (BCG), seismocardiograph (SCG) and respiration are measured using Magnetic Resonance Imaging (MRI) [23-25], in which the sensors are exposed to strong electromagnetic fields. Our unit also previously worked on analyzing the waveform of vital signs, with the intention of 
measuring blood pressure [26-29], blood glucose levels [30] and multiple vital signs [31,32]. The goal of these studies was to achieve continuous monitoring in the future.

A lot of methods have been researched and developed to measure FBG sensors [6,7]. These methods can be briefly classified into three types: (1) wavelength-swept filters, (2) interferometers and (3) passive filters. Firstly, the (1) wavelength-swept-type interrogators employ a wavelength-swept light source or measurement window $[33,34]$. This method has the advantage of being able to measure many FBGs simultaneously because it has an intrinsic wavelength division multiplexing (WDM) scheme. The (2) interferometer-type interrogators employ a kind of interferometer, such as q Mach-Zehnder $[8,35]$ or Michelson interferometer [36]. This has the great potential for measuring Bragg wavelength with extremely high precision $[8,36]$. These two methods have already been used in commercially available FBG interrogators. However, these methods have difficulty being downsized. Because the main application of the FBG sensors so far are for industrial or seismic sensing [8-12], this difficulty has not been a problem. However, when it comes to a continuous vital sign monitoring system, the size and weight of the measurement system is crucial.

In this study, we employed a (3) passive filter [37-39] to develop a portable FBG interrogation system. This system employs an edged filter as the wavelength measuring element, and is small and easy to use, with high precision. The limitation of this type is the limited range of Bragg wavelengths; however, this disadvantage is not a problem for plethymogram, because the signal amplitude is totally within their range. A signal amplification circuit was also developed, which effectively amplifies the plethysmograph signal, obtained as small vibrations of optical power on a large offset. The circuit also has the output port of the offset, which contains the information of the absolute value of the FBG wavelength. With this output, the conversion coefficients of the reflect/transmit ratio to wavelength are obtained. The developed system can interrogate two FBG sensors simultaneously with a $1-\mathrm{kHz}$ sampling rate and high repeatability (approximately $0.2 \mathrm{pm}$ ). With this interrogator, a plethysmograph of a brachial artery can be clearly obtained. The measured data are wirelessly sent to a laptop PC. A small, commercially available portable battery powers the interrogator, hence the whole system becomes portable.

\section{Edge Filter-Based FBG Interrogator}

\subsection{Principle of Edge Filter-Based FBG Interrogation}

The FBG is the periodical refractive index change inscribed in the optical fiber core. Figure 1 shows the schematic diagram of the FBG, and its effect on the incident light. The incident light propagates through the optical fiber core, and the FBG reflects only the specific wavelength of incident light determined by Equation (1),

$$
\lambda_{\mathrm{B}}=2 n_{\mathrm{eff}} d,
$$

where $\lambda_{\mathrm{B}}$ is the Bragg wavelength, $n_{\mathrm{eff}}$ is the effective refractive index and $d$ is the grating interval. Physical stress such as strain, tension, pressure and temperature cause $n_{\mathrm{eff}}$ and $d$ to shift, which are measured as a shift in $\lambda_{\mathrm{B}}$. 

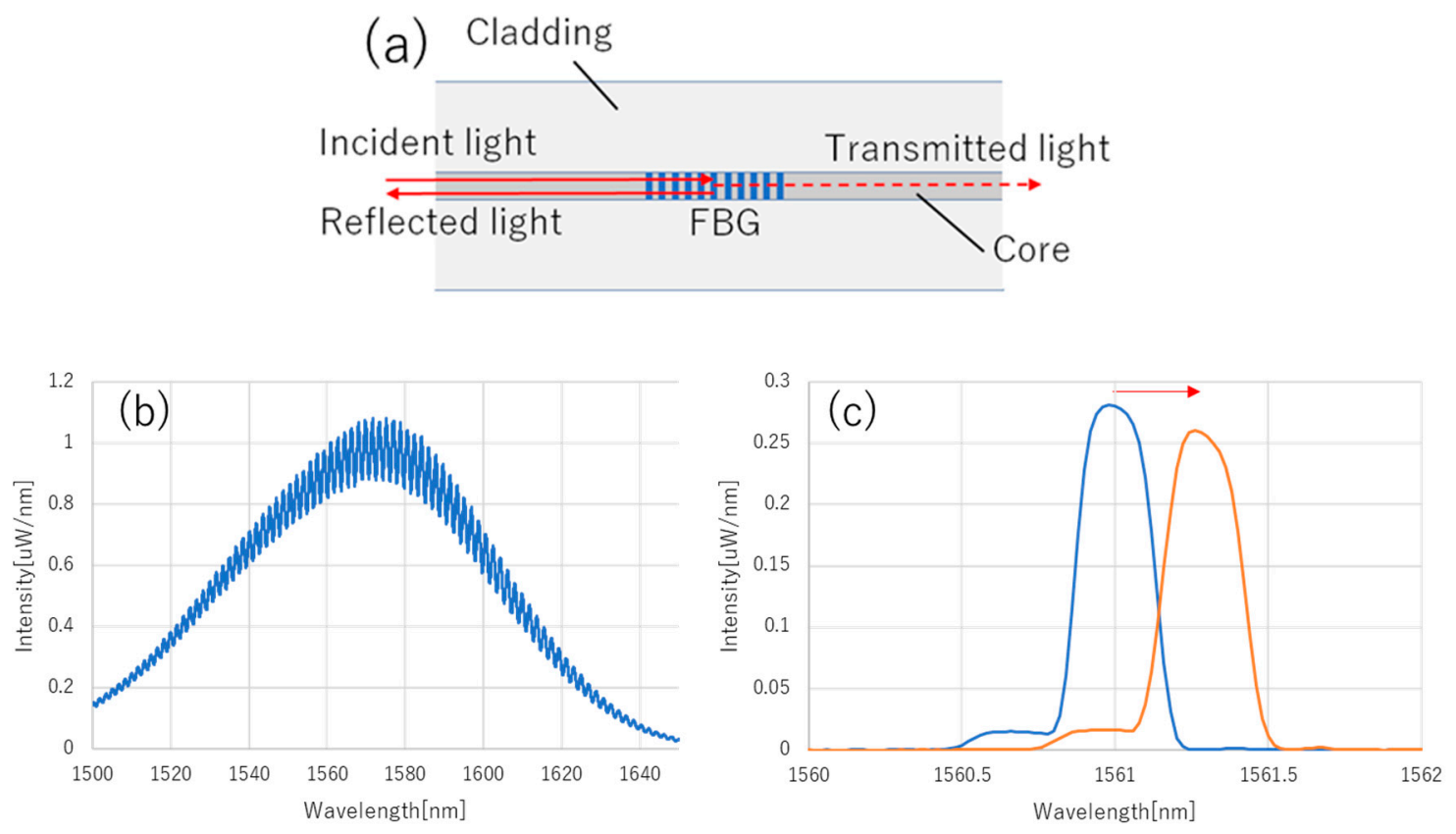

Figure 1. (a) The schematic diagram of the FBG sensor. The incident light propagates through the optical fiber core, which is surrounded by cladding. FBGs have a periodic refractive index change inscribed on the optical fiber core. An example of the incident light (b), and the real reflected spectrum of FBG and its change against tension (c) are shown in the graph. These spectrums are obtained with the optical spectrum analyzer (OSA) (AQ6370D, Yokogawa Electric Co., Tokyo, Japan) with a resolution setting of $0.1 \mathrm{~nm}$.

To demodulate the Bragg wavelength, a lot of methods [6-8,33-35] have been suggested. In this study, an optical edge filter was employed to achieve a simple measurement setup [37]. The optical edge filter is a kind of dielectric thin film, which is normally used as a WDM filter in a variety of applications such as telecommunications and sensor multiplexing. In such applications, a stopband and passband are used. On the other hand, the slope of the transmission/reflection ratio between the stopband and the passband is used for sensing [37]. Figure $2 b$ shows a typical wavelength dependence of the transmission/reflection ratio between the stopband and the passband of the edge filter. In this study, the slope of the edge filter is used to observe the Bragg wavelength change (in Figure $2 b$, indicated with a dashed square). Figure 2a shows the schematic diagram of typical experiment setups of the FBG interrogation. Because the transmission/reflection ratio of the edge filter is nearly a linear function of the wavelength, $\lambda_{\mathrm{B}}$ is expressed as follows:

$$
\lambda_{\mathrm{B}}=\alpha D+\beta,
$$

where $\mathrm{D}=(T-R) /(T+R)$ is the normalized differential signal [37] in which $T$ and $R$ denote the transmission and reflective light power of the edge filter, respectively, which is measured on the PDs. $\alpha$ and $\beta$ are the constants determined on each edge filter. The specific values are calculated in Section 3 . 


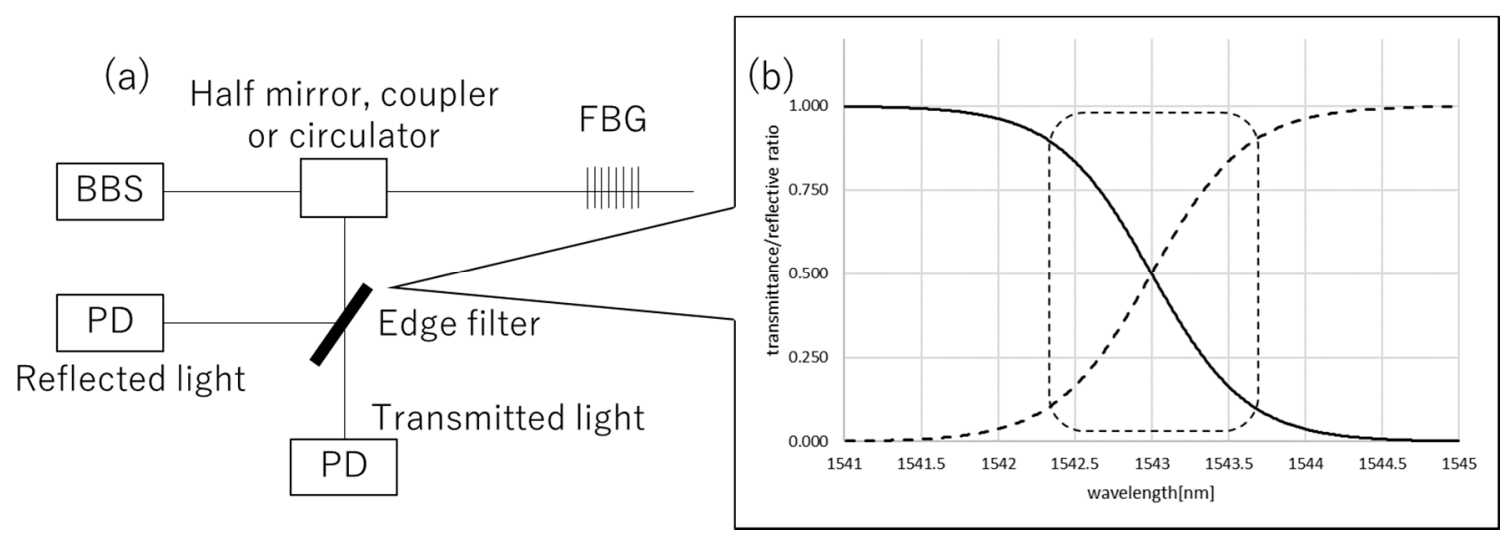

Figure 2. (a) Typical setup of the edge filter-based FBG interrogation. The light emitted from a broad band light source (BBS) enters the FBG and only the light of the Bragg wavelength is reflected. The reflected light enters the edge filter and is divided into the reflected and transmitted light, whose ratio depends on the wavelength, as in (b). These lights are observed by photo-detectors (PDs). (b) Conceptual diagram of the wavelength dependence of the transmission/reflection ratio of the edge filter. The dashed square indicates the slope used for FBG demodulation. The solid and dashed lines indicate the transmittance and reflectance ratio, respectively. The FBG wavelength is set in the dashed square range, in which the wavelength dependence could approximate a linear function.

\subsection{Characteristics of the Developed FBG Interrogator}

Firstly, throughout this study, the FBG (SU-CW-90-2-15-10-U-A-2-2R, Shinkodensen co.ltd., Kagawa, Japan) was used as a specimen, which was inscribed in a PANDA-type polarization-maintaining (PM) fused silica optical fiber. A single-mode fiber is more cost effective; however, it could not be used here because the edge filters have polarization-dependent loss, and the SLD (Super Luminescent Diode) emits polarized light. For continuous vital sign monitoring, we developed the edge filter module and the amplifier circuit (Figure 3, schematic diagram Figure 4). This module contains a super luminescent diode (SLD, the spectrum is shown in Figure 1), five photo-detectors (PD, KPDE030-SW, KYOTO SEMICONDUCTOR Co., Ltd., Kyoto City, Japan), a WDM filter, a half mirror (a 1:1 beam splitter which has polarization dependent loss less than $3 \%$ ), a physical contact type standard connector (SC/PC) pigtail and two edge filters. Here, the WDM filter is used for just dividing two FBGs to measure simultaneously. The incident light emitted from the SLD is transmitted through the pigtail and reflected by the FBG, then the reflected light counter-propagates and, finally, is observed by the PDs. The PDs convert the reflected light to the electrical current:

$$
\mathrm{y}=\mathrm{ax}
$$

where $y$ is the electrical current, $a$ is conversion coefficient and $x$ is incident light power. Each of these currents enter the amplifier circuit, shown in Figure $4 \mathrm{~b}$. The current-voltage converter converts this current signal to the voltage:

$$
\mathrm{z}=\text { by, }
$$

where $\mathrm{z}$ is output voltage of the current-voltage converter, and $\mathrm{b}$ is conversion coefficient (Figure $4 \mathrm{~b}$ ). In our previous study, it was revealed that the plethysmograph signal we intend to measure was as much as one-thousand times smaller than the offset power [29]. Hence, if the signal is simply amplified, the amplified voltage would easily exceed the range of the analog-to-digital converter (ADC) and the intended signal would not be sufficiently amplified. To overcome this difficulty, a low-pass filter (LPF) and differential amplifier is employed, hence the dynamic signal is largely amplified separately. 


$$
\begin{aligned}
& \mathrm{z}_{\text {off }}=\frac{1}{\tau} \int_{\mathrm{t}-\tau}^{\mathrm{t}} z\left(t^{\prime}\right) d t^{\prime}, \\
& \mathrm{z}_{\text {dyn }}=\mathrm{c}\left(\mathrm{z}-\mathrm{z}_{\mathrm{off}}\right),
\end{aligned}
$$

where $z_{\text {off }}$ is the offset power of $z, z_{d y n}$ is the amplified dynamic signal, $\tau$ is the time constant of the low-pass filter and $\mathrm{c}$ is the amplification factor of the differential amplifier, which is set to 100 . The offset power $\mathrm{z}_{\text {off }}$ is also output (Figure 4 ) and used to evaluate the conversion formula between the normalized differential signal to the wavelength (Figure 5). The data acquisition device (USB6210, National Instruments Corporation, Austin, TX, USA) and LabVIEW are used to measure and analyze the signal. The OSA is used to measure the Bragg wavelength corresponding to each normalized differential value obtained with the edge filter module and developed amplifier circuit. To evaluate the coefficient of Equation (2), a wavelength-tunable FBG filter is used (Figure 6). Figure 6 shows the relationship between the wavelength and the normalized differential signal. The dashed lines indicate the approximations $\lambda_{\mathrm{B}}=1.3321 \mathrm{D}+1542.9567$ and $\lambda_{\mathrm{B}}=-1.6497 \mathrm{D}+1560.5514$ for 1543 and $1561 \mathrm{~nm}$-centered edge filters, respectively.

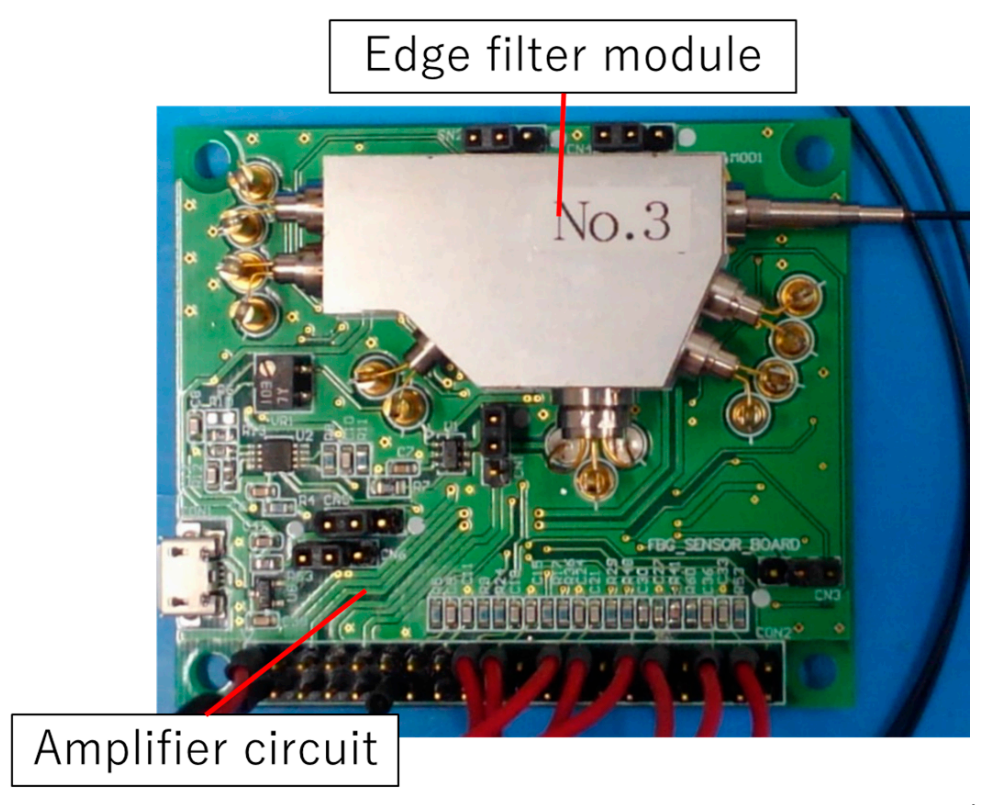

Figure 3. The edge filter module and amplifier circuit. The module contains an SLD, five PDs, a WDM, a half mirror, a SC/PC-pigtail and two edge filters. 

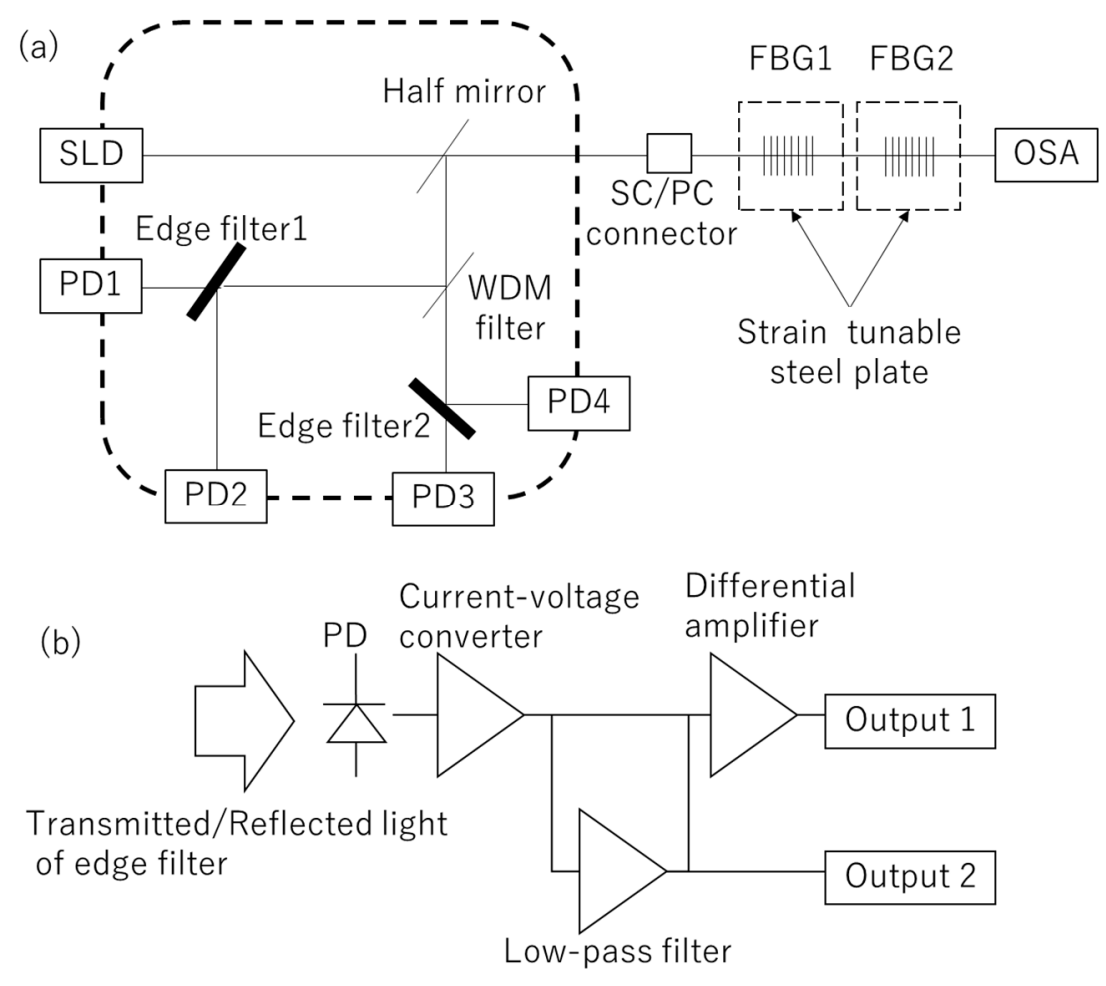

Figure 4. Schematic diagram of the edge filter module and amplifier circuit. (a) The schematic diagram of the developed edge filter module. In addition to Figure 2a, this module contains a WDM filter to measure two FBGs with different center wavelengths. Corresponding to each FBG, two edge filters are used. (b) The schematic diagram of the amplifier circuit. Each PD converts the light into an electrical current, then the current-voltage converter converts this into voltage. This voltage is divided into two paths: the first path enters the low-pass filter (LPF) to output the slower signal (output 2). The other is amplified by the differential amplifier with the output voltage of the low-pass filter to obtain a largely amplified faster signal (output 1).

To obtain the amplified dynamic signal as in the unit of wavelength, the following equations are used. In the application of the plethysmogram, which is the main objective of this interrogator, repeatability (standard deviation) of the measured wavelength is crucial. The standard deviation of measured FBG wavelengths, which are in static circumstance, are 0.13 and $0.08 \mathrm{pm}$ for 1543 and $1561 \mathrm{~nm}$-centered FBGs, respectively. In a previous study, it was confirmed that the wavelength change caused by the plethysmogram on the radial artery was several picometers to several tens of picometers [26], so we assume that the interrogator developed in this study is applicable to the plethysmogram measurement. 

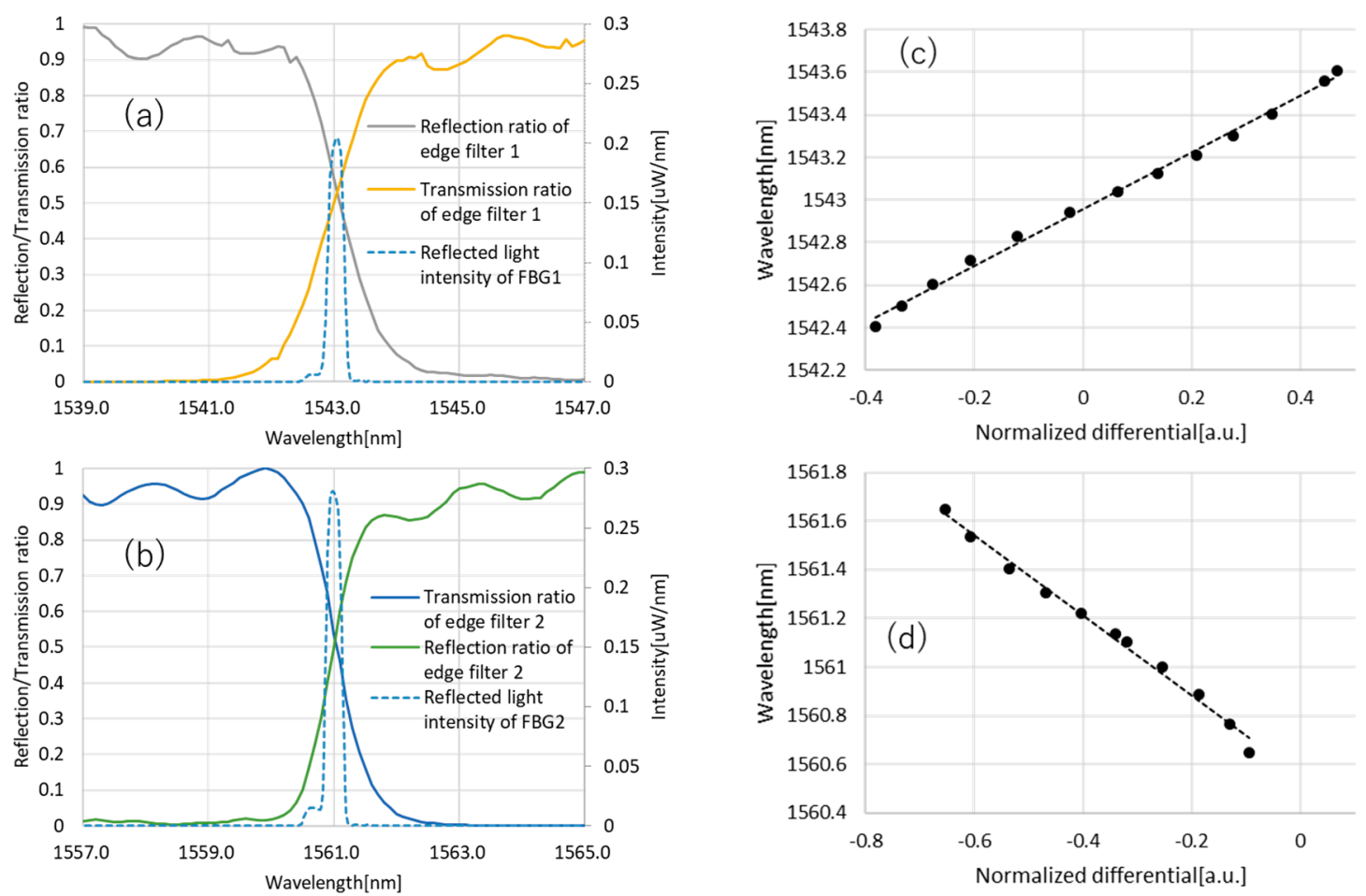

Figure 5. (a,b) The spectrums of the (a) 1543 and (b) 1561 nm-centered edge filters and FBGs. (c,d) The results of the Bragg wavelength vs normalized differential signal of the (c) 1543 and (d) $1561 \mathrm{~nm}$-centered edge filters. Dashed lines indicate the linear approximation of the data. The formulas are $\lambda_{B}=1.3321 \mathrm{D}+1542.9567$ and $\lambda_{\mathrm{B}}=-1.6497 \mathrm{D}+1560.5514$ for the 1543 and $1561 \mathrm{~nm}$-centered edge filters, respectively.

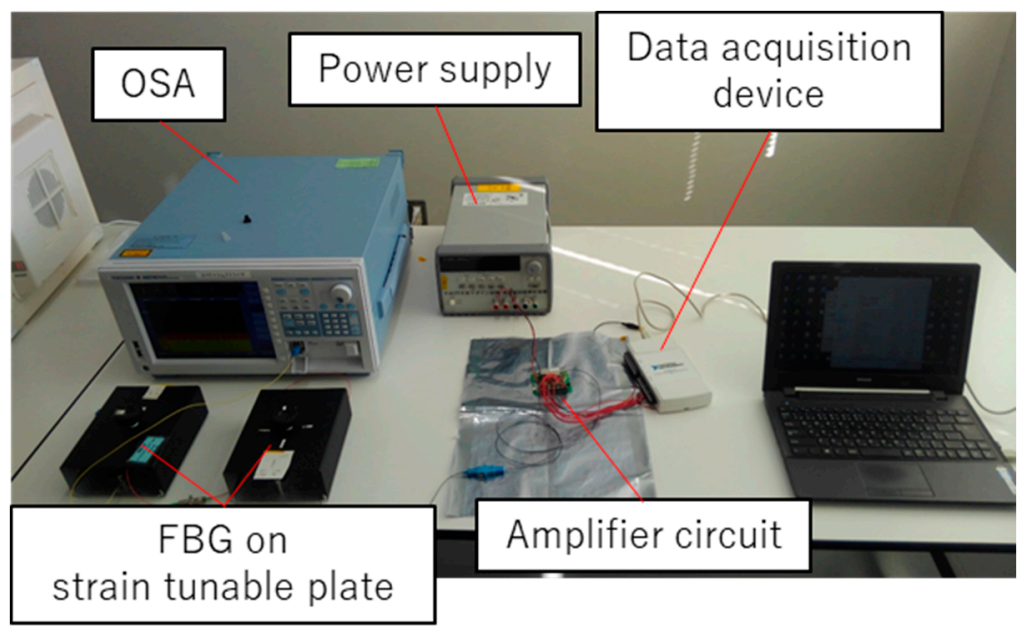

Figure 6. The measurement setup of the experiment to obtain the coefficient of the normalized differential to wavelength conversion formula, with 1543- and 1561-nm-centered FBGs glued separately on a steel plate, with the strain is controlled manually. The transmitted light of the FBGs is measured using an OSA, on which the Bragg wavelengths are calculated. 


\section{Application to Vital Sign Monitoring}

\subsection{Principle and Setup}

In this section, we tried to measure the plethysmograph on a brachiral artery. To analyze the data, a Butterworth-type bandpass filter was employed to reduce the noise and compare the waveforms. To achieve a remote and portable measurement system, a single-board computer (Zynq-7010, Xilinx, San Jose, CA, USA) and smaller AD board (High-Precision AD/DA Board, Waveshare Electronic, Shenzhen, China) were used to measure the output voltage of the edge filter module. These boards were encased in a case made by a 3D printer (Figure 7). The size of the case was $74 \times 57 \times 90 \mathrm{~mm}$, and the weight was $230 \mathrm{~g}$, which was small enough to be portable. The power consumption was about $0.8 \mathrm{~W}$. This system only measured the $z_{\mathrm{T}, \mathrm{dyn}}$ and $z_{\mathrm{R}, \mathrm{dyn}}$ shown in Equation (6), from which the wavelength shift is approximated:

$$
\Delta \lambda=\frac{\alpha\left\{\left(z_{\mathrm{T}, \mathrm{dyn}}-z_{\mathrm{R}, \mathrm{dyn}}\right)-\left(z_{\mathrm{T}, \mathrm{dyn}}^{0}-z_{\mathrm{R}, \mathrm{dyn}}^{0}\right)\right\}}{c\left(z_{\mathrm{T}, \mathrm{off}}-z_{\mathrm{R}, \mathrm{off}}\right)},
$$

where $z_{\mathrm{T}, \mathrm{dyn}}^{0}$ and $z_{\mathrm{R}, \mathrm{dyn}}^{0}$ are the initial values of $z_{\mathrm{T}, \mathrm{dyn}}$ and $z_{\mathrm{R}, \mathrm{dyn}}$, respectively; $\alpha, z_{\mathrm{T} \text {,off }}$ and $z_{\mathrm{R}, \text { off }}$ are determined in the experiment in Figure $5 \mathrm{c}$,d. Here, $\alpha=1.3321, z_{\mathrm{T}, \mathrm{off}}=0.08966$ and $z_{\mathrm{R}, \mathrm{off}}=0.07881$ for the 1543-nm-centered FBG, and $\alpha=-1.6497, z_{\mathrm{T}, \text { off }}=0.13802$ and $z_{\mathrm{R}, \mathrm{off}}=0.23218 . \quad \mathrm{c}=100$ is an amplification coefficient determined in the amplifier circuit. The data were sent to a laptop PC via Wi-Fi (a USB dongle was employed on a single-board computer (GW-USNano2, PLANEX COMMUNICATIONS INC., Tokyo, Japan)) and analyzed in LabVIEW. The FBG interrogator developed in this study was used for vital sign monitoring; Figure 8 shows the measurement setup of this experiment. The 1543 and $1561 \mathrm{~nm}$-centered FBG sensors were taped with surgical tape on the brachial artery of the subject (inset of Figure 8). Another 1550 nm-centered FBG inscribed on single-mode fiber was also used as reference, and measured with a commercially available FBG interrogator (PF20, Naganokeiki Co., Ltd., Nagano, Japan).

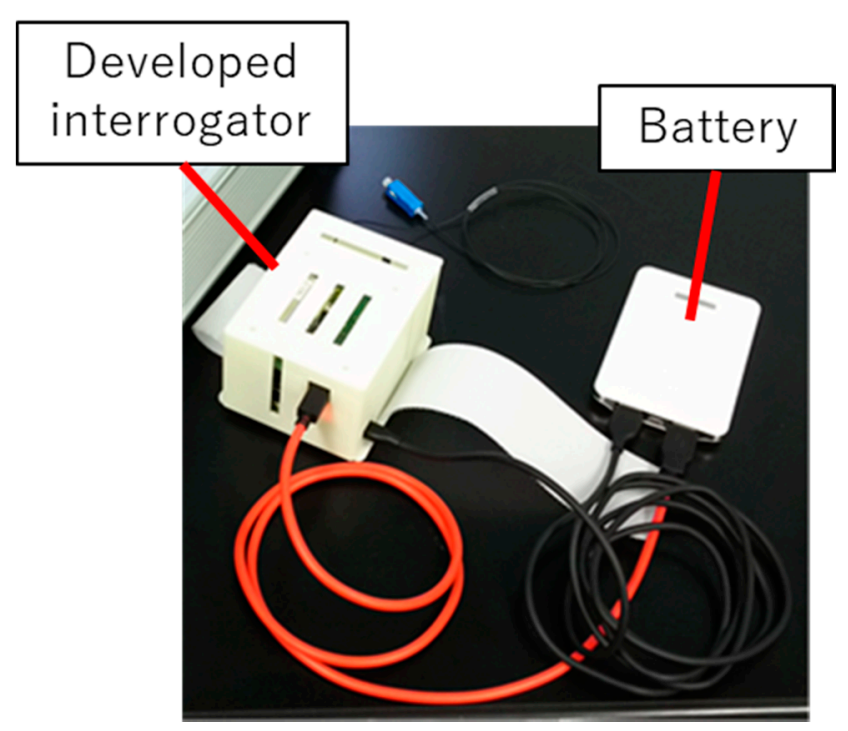

Figure 7. The casing of the interrogator (left). The edge filter module, single-board computer and smaller AD board are encased. A portable battery (right) supplies the power. 


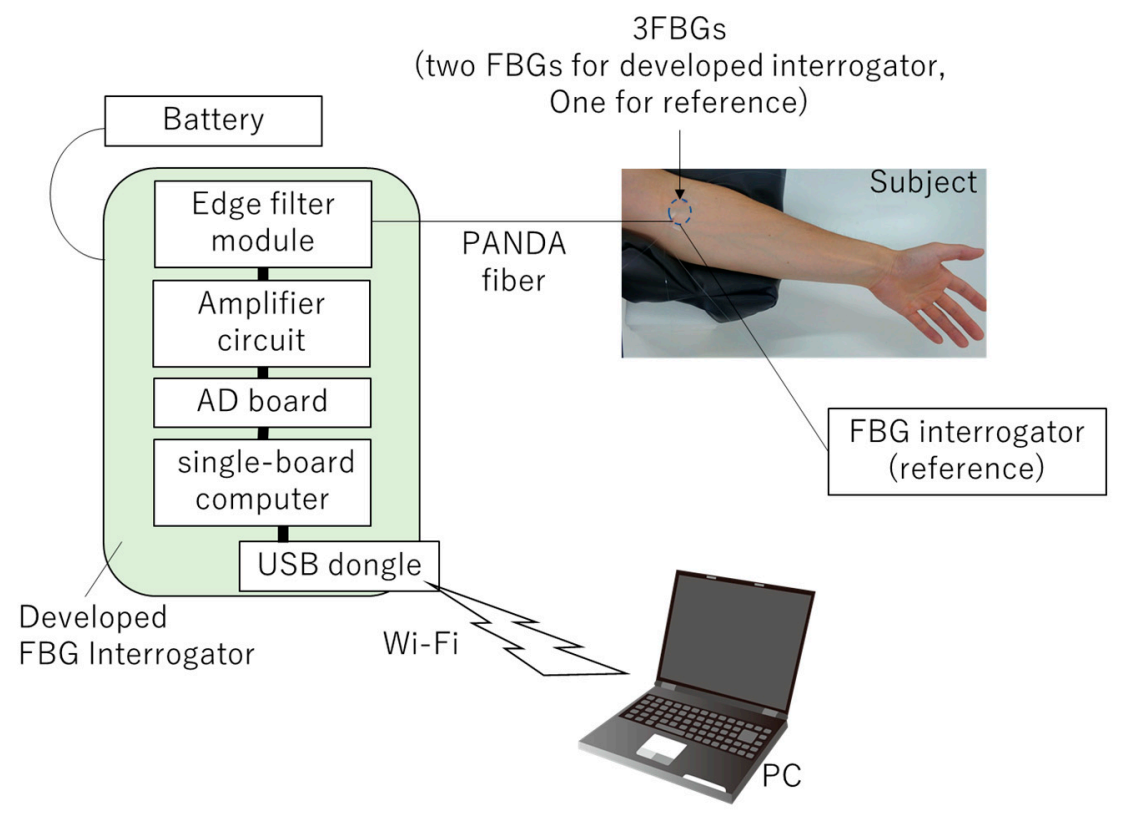

Figure 8. The settings of the plethysmograph measurement. The FBG sensor is taped near the brachial artery. Measured data are saved on a PC, which is connected to the interrogator via Wi-Fi.

\subsection{Results and Discussion}

Figure 9 shows a plethysmograph obtained on the brachial artery with three FBGs, two for the developed interrogator with wavelengths centered to 1543 (FBG1) and 1561 (FBG2) nm, and another one centered to $1550 \mathrm{~nm}$ (reference). The protocol of this study was approved by the Ethics Committee of Shinshu University (Project identification code: No. 3202, Verification clinical trial with wearable vital sign measurement system). The subject was a 27 -year-old male without any health problems. The sampling rate was $1 \mathrm{kHz}$ for both interrogators. The pulse wave peaks were clearly obtained at the same time, and their amplitudes were about $5 \mathrm{pm}$ and consistent with each other.

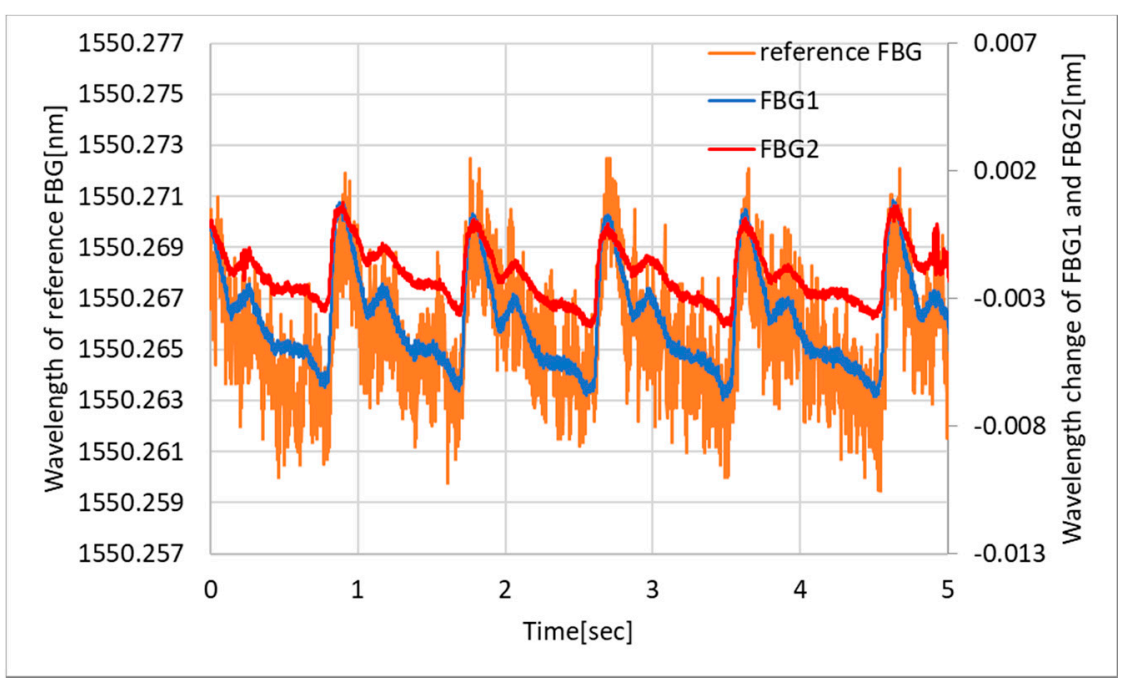

Figure 9. Plethysmogram obtained with the developed FBG interrogator and commercially available interrogator.

To obtain more details of the waveform, the data was processed with the Butterworth bandpass filter (order 2, low-cutoff frequency $0.5 \mathrm{~Hz}$, high-cutoff frequency $5 \mathrm{~Hz}$ ). The filtered plethysmogram is shown in Figure 10. Qualitatively, the FBG1 and FBG2 show similar waveforms, which indicate 
two local maximums next to the pulse wave peaks. The reference FBG also shows a similar tendency; however, the repeatability is worse because of the higher standard deviation, which is apparently shown in Figure 9, calculated as $0.1 \mathrm{pm}$.

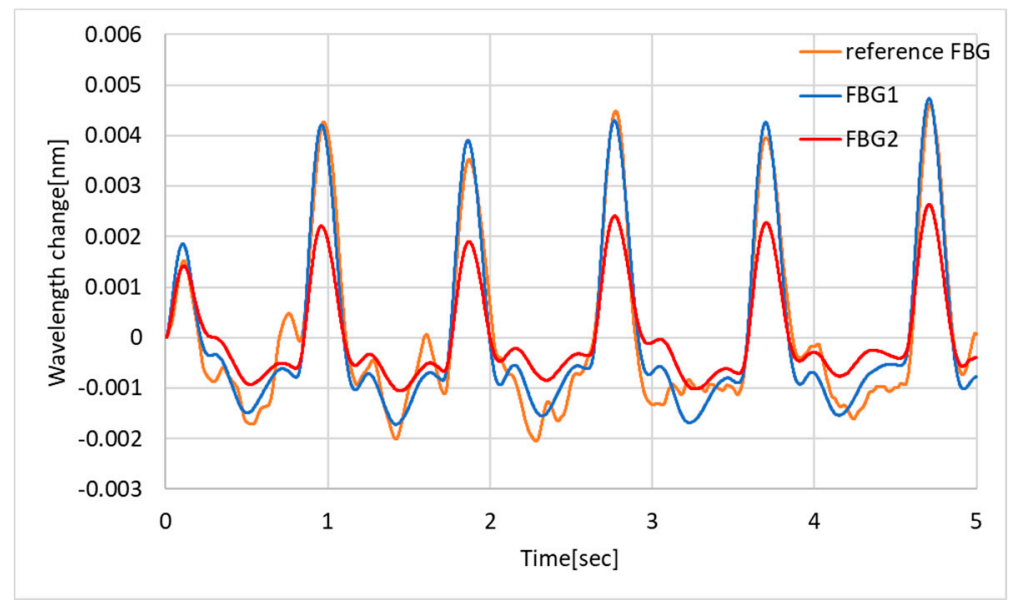

Figure 10. A Butterworth-type bandpass filter (order 2, low-cutoff frequency $0.5 \mathrm{~Hz}$, high-cutoff frequency $5 \mathrm{~Hz}$ ) is applied onto the data of Figure 9. The offset value of the reference FBG is subtracted before filtering.

\section{Conclusions}

A small, high-precision FBG interrogator was developed and evaluated. The interrogator employed an edge filter module with two wavelength channels, 1543 and $1561 \mathrm{~nm}$. By dividing the low-frequency and high-frequency signals and amplifying them independently, the standard deviation of the measured wavelength was suppressed to $0.13 \mathrm{pm}$ for the 1543-nm-centered FBG and $0.08 \mathrm{pm}$ for the 1561-nm-centered one. The developed interrogator was applied to plethysmograph measurement on the brachial artery. As a result, the peaks of the heartbeat were clearly obtained, and their calculated amplitude of wavelength change was consistent with the reference FBG sensor. To transmit the data through Wi-Fi, we used a commercially available single-board computer, then the size of the whole interrogator was enlarged. However, the edge filter module itself has large potential to be reduced in size. The developed system indicates the viability of continuous, wearable vital sign monitoring in the future.

Author Contributions: K.O. and K.F. (Keisaku Fujimoto) conceived methodology; K.O. and Y.H. performed the experiments; S.K, K.F. (Keiichi Fujita), H.I. and K.F. (Keisaku Fujimoto) supervisioned this study; K.O. wrote the paper.

Funding: This research was (partially) supported by the Creation of a development platform for implantable/wearable medical devices by a novel physiological data integration system of the Program on Open Innovation Platform with Enterprises, Research Institute and Academia (OPERA) from the Japan Science and Technology Agency (JST) Grant Number JPMJOP1722. This work was also supported by JSPS KAKENHI Grant Number JP16H01805 and the Wearable vital signs measurement system development project at Shinshu University.

Acknowledgments: We appreciate Tedra Elliot proofing this article.

Conflicts of Interest: The authors declare no conflict of interest.

\section{References}

1. Galeotti, L.; Scully, C.G. A method to extract realistic artifacts from electrocardiogram recordings for robust algorithm testing. J. Electrocardiol. 2018, 51, S56-S60. [CrossRef] [PubMed]

2. Sa-Ngasoongsong, A.; Kunthong, J.; Sarangan, V.; Cai, X.; Bukkapatnam, S.T. A low-cost, portable, high-throughput wireless sensor system for phonocardiography applications. Sensors 2012, 12, 10851-10870. [CrossRef] [PubMed] 
3. Warren, K.; Harvey, J.; Chon, K.; Mendelson, Y. Improving pulse rate measurements during random motion using a wearable multichannel reflectance photoplethysmograph. Sensors 2016, 16, 342. [CrossRef] [PubMed]

4. Wei, P.; Guo, R.; Zhang, J.; Zhang, Y.T. A new wristband wearable sensor using adaptive reduction filter to reduce motion artifact. In Proceedings of the 2008 International Conference on Information Technology and Applications in Biomedicine, Shenzhen, China, 30-31 May 2008; pp. 278-281.

5. Hill, K.O.; Meltz, G. Fiber Bragg grating technology fundamentals and overview. J. Lightwave Technol. 1997, 15, 1263-1276. [CrossRef]

6. Kersey, A.D.; Davis, M.A.; Patrick, H.J.; LeBlanc, M.; Koo, K.P.; Askins, C.G.; Putnam, M.A.; Friebele, E.J. Fiber grating sensors. J. Lightwave Technol. 1997, 15, 1442-1463. [CrossRef]

7. Rajan, G. Optical Fiber Sensors: Advanced Techniques and Applications; CRC Press: Boca Raton, FL, USA, 2015.

8. Yoshino, T.; Sano, Y.; Ota, D.; Fujita, K.; Ikui, T. Fiber-Bragg-grating based single axial mode Fabry-Perot interferometer and its strain and acceleration sensing applications. J. Lightwave Technol. 2016, 34, 2241-2250. [CrossRef]

9. Chan, T.H.; Yu, L.; Tam, H.-Y.; Ni, Y.-Q.; Liu, S.Y.; Chung, W.H.; Cheng, L.K. Fiber Bragg grating sensors for structural health monitoring of Tsing Ma bridge: Background and experimental observation. Eng. Struct. 2006, 28, 648-659. [CrossRef]

10. Majumder, M.; Gangopadhyay, T.K.; Chakraborty, A.K.; Dasgupta, K.; Bhattacharya, D.K. Fibre Bragg gratings in structural health monitoring-Present status and applications. Sens. Actuators A Phys. 2008, 147, 150-164. [CrossRef]

11. Laffont, G.; Roussel, N.; Rougeault, S.; Boussoir, J.; Maurin, L.; Ferdinand, P. Innovative FBG sensing techniques for the railway industry: Application to overhead contact line monitoring. In Proceedings of the 20th International Conference on Optical Fibre Sensors, International Society for Optics and Photonics, Edinburgh, UK, 5-9 October 2009; Volume 7503, p. 75035K.

12. Bocciolone, M.; Bucca, G.; Collina, A.; Comolli, L. Pantograph-catenary monitoring by means of fibre Bragg grating sensors: Results from tests in an underground line. Mech. Syst. Signal Process. 2013, 41, $226-238$. [CrossRef]

13. Takahashi, N.; Yoshimura, K.; Takahashi, S.; Imamura, K. Development of an optical fiber hydrophone with fiber Bragg grating. Ultrasonics 2000, 38, 581-585. [CrossRef]

14. Fisher, N.E.; Webb, D.J.; Pannell, C.N.; Jackson, D.A.; Gavrilov, L.R.; Hand, J.W.; Zhang, L.; Bennion, I. Ultrasonic hydrophone based on short in-fiber Bragg gratings. Appl. Opt. 1998, 37, 8120-8128. [CrossRef] [PubMed]

15. Koyama, S.; Sakaguchi, A.; Ishizawa, H.; Yasue, K.; Oshiro, H.; Kimura, H. Vital Sign Measurement Using Covered FBG Sensor Embedded into Knitted Fabric for Smart Textile. J. Fiber Sci. Technol. 2017, 73, 300-308. [CrossRef]

16. Sakaguchi, A.; Kato, M.; Ishizawa, H.; Kimura, H.; Koyama, S. Fabrication of optical fiber embedded knitted fabrics for smart textiles. J. Text. Eng. 2016, 62, 129-134. [CrossRef]

17. Roriz, P.; Carvalho, L.; Frazão, O.; Santos, J.L.; Simões, J.A. From conventional sensors to fibre optic sensors for strain and force measurements in biomechanics applications: A review. J. Biomech. 2014, 47, 1251-1261. [CrossRef] [PubMed]

18. Gurkan, D.; Starodubov, D.; Yuan, X. Monitoring of the heartbeat sounds using an optical fiber Bragg grating sensor. In Proceedings of the SENSORS, 2005 IEEE, Irvine, CA, USA, 30 October-3 November 2005; p. 4.

19. Zhang, C.; Miao, C.; Gao, H.; Gan, J.; Li, H.-Q. Research on fiber Bragg grating heart sound sensing and wavelength demodulation method. In Proceedings of the Advanced Sensor Systems and Applications IV, International Society for Optics and Photonics, Beijing, China, 18-20 October 2010; Volume 7853, p. 78531Q.

20. Allsop, T.; Lloyd, G.; Bhamber, R.S.; Hadzievski, L.; Halliday, M.; Webb, D.J.; Bennion, I. Cardiac-induced localized thoracic motion detected by a fiber optic sensing scheme. J. Biomed. Opt. 2014, 19, 117006. [CrossRef] [PubMed]

21. Silva, A.F.; Carmo, J.P.; Mendes, P.M.; Correia, J.H. Simultaneous cardiac and respiratory frequency measurement based on a single fiber Bragg grating sensor. Meas. Sci. Technol. 2011, 22, 075801. [CrossRef]

22. Presti, D.L.; Massaroni, C.; Formica, D.; Saccomandi, P.; Giurazza, F.; Caponero, M.A.; Schena, E. Smart textile based on 12 fiber Bragg gratings array for vital signs monitoring. IEEE Sens. J. 2017, 17, 6037-6043. [CrossRef] 
23. Dziuda, L.; Krej, M.; Skibniewski, F.W. Fiber Bragg grating strain sensor incorporated to monitor patient vital signs during MRI. IEEE Sens. J. 2013, 13, 4986-4991. [CrossRef]

24. Massaroni, C.; Saccomandi, P.; Formica, D.; Presti, D.L.; Caponero, M.A.; Di Tomaso, G.; Giurazza, F.; Muto, M.; Schena, E. Design and feasibility assessment of a magnetic resonance-compatible smart textile based on fiber Bragg grating sensors for respiratory monitoring. IEEE Sens. J. 2016, 16, 8103-8110. [CrossRef]

25. Nedoma, J.; Fajkus, M.; Novak, M.; Strbikova, N.; Vasinek, V.; Nazeran, H.; Vanus, J.; Perecar, F.; Martinek, R. Validation of a novel fiber-optic sensor system for monitoring cardiorespiratory activities during mri examinations. Adv. Electr. Electron. Eng. 2017, 15, 536-543. [CrossRef]

26. Miyauchi, Y.; Koyama, S.; Ishizawa, H. Basic experiment of blood-pressure measurement which uses FBG sensors. In Proceedings of the 2013 IEEE International Instrumentation and Measurement Technology Conference (I2MTC), Minneapolis, MN, USA, 6-9 May 2013; pp. 1767-1770.

27. Katsuragawa, Y.; Ishizawa, H. Non-invasive blood pressure measurement by pulse wave analysis using FBG sensor. In Proceedings of the 2015 IEEE International Instrumentation and Measurement Technology Conference (I2MTC) Proceedings, Pisa, Italy, 11-14 May 2015; pp. 511-515.

28. Koyama, S.; Ishizawa, H.; Fujimoto, K.; Chino, S.; Kobayashi, Y. Influence of individual differences on the calculation method for FBG-type blood pressure sensors. Sensors 2017, 17, 48. [CrossRef] [PubMed]

29. Haseda, Y.; Ishizawa, H.; Koyama, S.; Ogawa, K.; Fujita, K.; Chino, S.; Fujimoto, K. Fundamental Research of Pulse Wave and Blood Pressure Measurement Using Passive Edged Filter Integrated in Fiber Bragg Grating Measurement System. Proc. IEEE SICE 2018.

30. Kurasawa, S.; Koyama, S.; Ishizawa, H.; Fujimoto, K.; Chino, S. Verification of Non-Invasive Blood Glucose Measurement Method Based on Pulse Wave Signal Detected by FBG Sensor System. Sensors 2017, 17, 2702. [CrossRef]

31. Miyauchi, Y.; Ishizawa, H.; Niimura, M. Measurement of Pulse Rate and Respiration Rate Using Fiber Bragg Grating Sensor. Trans. Soc. Instrum. Control Eng. 2013, 49, 1101-1105. [CrossRef]

32. Ogawa, K.; Koyama, S.; Ishizawa, H.; Fujiwara, S.; Fujimoto, K. Simultaneous Measurement of Heart Sound, Pulse Wave and Respiration with Single Fiber Bragg Grating Sensor. In Proceedings of the 2018 IEEE International Symposium on Medical Measurements and Applications (MeMeA), Rome, Italy, 11-13 June 2018; pp. 1-5.

33. Yun, S.H.; Richardson, D.J.; Kim, B.Y. Interrogation of fiber grating sensor arrays with a wavelength-swept fiber laser. Opt. Lett. 1998, 23, 843-845. [CrossRef]

34. Nakazaki, Y.; Yamashita, S. Fast and wide tuning range wavelength-swept fiber laser based on dispersion tuning and its application to dynamic FBG sensing. Opt. Express 2009, 17, 8310-8318. [CrossRef] [PubMed]

35. Todd, M.D.; Johnson, G.A.; Chang, C.C. Passive, light intensity-independent interferometric method for fibre Bragg grating interrogation. Electron. Lett. 1999, 35, 1970-1971. [CrossRef]

36. Léguillon, Y.; Tow, K.H.; Besnard, P.; Mugnier, A.; Pureur, D.; Doisy, M. First demonstration of a 12 DFB fiber laser array on a $100 \mathrm{GHz}$ ITU grid, for underwater acoustic sensing application. In Proceedings of the Optical Sensing and Detection II, International Society for Optics and Photonics, Brussels, Belgium, 16-19 April 2012; Volume 8439, p. 84390J.

37. Davis, M.A.; Kersey, A.D. All-fibre Bragg grating strain-sensor demodulation technique using a wavelength division coupler. Electron. Lett. 1994, 30, 75-77. [CrossRef]

38. Díaz, C.; Leitão, C.; Marques, C.; Domingues, M.; Alberto, N.; Pontes, M.; Frizera, A.; Ribeiro, M.; André, P.; Antunes, P. Low-cost interrogation technique for dynamic measurements with fbg-based devices. Sensors 2017, 17, 2414. [CrossRef]

39. Díaz, C.A.; Marques, C.A.; Domingues, M.F.F.; Ribeiro, M.R.; Frizera-Neto, A.; Pontes, M.J.; André, P.S.; Antunes, P.F. A cost-effective edge-filter based FBG interrogator using catastrophic fuse effect micro-cavity interferometers. Measurement 2018, 124, 486-493. [CrossRef]

(C) 2019 by the authors. Licensee MDPI, Basel, Switzerland. This article is an open access article distributed under the terms and conditions of the Creative Commons Attribution (CC BY) license (http://creativecommons.org/licenses/by/4.0/). 